\title{
Research on the Investment and Financing Mode of Chinese Overseas Infrastructure Construction under the Background of the "Belt and Road" Initiative
}

\author{
Yuxuan Jiang \\ International Business School \\ YNUFE \\ Yunnan, China \\ 825585020@qq.com
}

\author{
Honglie Zhang* \\ International Business School \\ YNUFE \\ Yunnan, China \\ yufehelen@126.com
}

\begin{abstract}
Under the "Belt and Road" initiative, to realize the interconnection of regional countries' infrastructure is important .The pace of overseas infrastructure construction of China has been accelerating in recent years, thus investment and financing models have gradually diversified. Many years of experience in infrastructure construction have enabled China to form a relatively complete export model, we will be able to open up new international markets for Chinese advantageous production capacity while alleviating bottlenecks in infrastructure construction along the country's borders. However, in the process of overseas infrastructure construction investment and financing in China, it also faces many risks and challenges. To solve these problems has strong practical significance.
\end{abstract}

Keywords - the "Belt and Road" initiative; infrastructure construction; Investment and Financing Models

\section{INTRODUCTION}

In 2013, Chinese President Xi Jinping proposed successively the strategic concept of building the "Silk Road Economic Belt" and "21st Century Maritime Silk Road" ( The" Belt and Road" initiative) jointly during his visit to Central Asia and Southeast Asian countries. One of the focal points is infrastructure connectivity. As the "longest-spanning economic corridor in the world", the" Belt and Road" initiative centers on China, with the Asia-Pacific Economic Circle on the east and the European Economic Circle on the west, involving a total economic volume of approximately US\$21 trillion. The "Belt and Road" economic corridors along the hinterland are mostly emerging economies and developing countries. Many countries are facing difficulties in capital, technology shortages, resource constraints, and backward infrastructure construction. China has advantages in capital reserves, technology, equipment, management and operation, they are highly compatible with the economic needs and development prospects of these countries. The" Belt and Road" initiative provides an inclusive global cooperation and development platform between China and countries along the route, finding a meeting point that can achieve cooperation and win-win. Therefore, research on infrastructure construction of China and the countries along the way has important strategic significance.

\section{BACKGROUND OF DOMESTIC AND FOREIGN} INFRASTRUCTURE CONSTRUCTION AND CHINESE POSITIONING

The realization of infrastructure interconnection is a priority area and key link of the "Belt and Road" Initiative. Infrastructure is a typical public good, and its basic and social benefits in construction and use are significant, and it has a substantial catalytic effect on economic growth. However, because of the characteristics of high investment cost and risk, long construction period and long return period, it is called "barbed rose". The demand for infrastructure funds along the "Belt and Road" Initiative infrastructure is huge and universal. According to the data of Asian Development Bank, during 2010 to 2020, the demand for funds for infrastructure construction in Asia alone was as high as US\$8.22 trillion. However, the Asian Development Bank only provides US $\$ 10$ billion in loans each year for infrastructure projects. The developing countries along the route are limited to the level of economic development, the financial strength is relatively weak, and the supply of funds is seriously inadequate, and it is difficult to undertake the task of building infrastructure independently.

The experience of infrastructure construction in recent 30 years has enabled China to have strong capability of infrastructure construction and supply. China has formed a relatively complete output model. Therefore, the construction of overseas infrastructure by Chinese enterprises can not only alleviate the bottleneck of the national infrastructure construction along the route, but also foster the emerging international market for China's advantageous capital, stimulate the output of related industries' production, exports and labor services. It can promote the economic integration of Asia and Europe, achieving mutual benefit and win-win situation [1]

Current situation of Investment and Financing Models for Overseas Infrastructure Construction

*Corresponding author 
The countries along the "Belt and Road" economic corridor are numerous and the infrastructure construction is relatively imperfect. In addition, the national conditions and financial systems in different countries are not the same. Chinese enterprises' overseas infrastructure construction requires the cooperation of various financial investments and financing models.

As a result, various innovative investment and financing models have gradually been introduced in the field of overseas infrastructure construction, such as build-operate-transfer (BOT model), public-private partnership (PPP model), etc. Thus, the investment and financing model for infrastructure construction in various countries has also changed. The general contracting has been transformed into investment and construction and operation and management; from the original financial investment model mainly played by the government at the leading role of investment, it has evolved into a diversified investment model.

\section{A. Use Development Finance to Obtain Investment and Financing Models}

In view of the inherent characteristics of large cross-border investment in infrastructure construction and long period of time, especially for large projects such as energy, commercial funds are rarely involved. Therefore, the establishment of a government-invested financial institution is imminent. The Chinese government put forward to "establish a development financial institution that serves the purpose of serving the country's development strategy", combining the country's credit with market-oriented operations, and using long-term investment and financing as a means to upgrade traditions. Policy-based bank effectiveness, which leads to a new form of low-cost finance. In the" Belt and Road" initiative, the Chinese government initiated the establishment of an Asian Infrastructure Investment Bank in 2015 in order to allow Chinese companies to obtain more infrastructure investment opportunities overseas. Investment Banking, and collaborating with many countries to establish the BRICS Development Bank to provide an effective channel for the financing of infrastructure in the neighboring countries. The establishment of the Silk Road Fund is another important measure of the Chinese government's " Belt and Road" initiative. At the same time, our government once again injected funds into the China Development Bank and the Export-Import Bank of China to provide financing support for the construction of numerous overseas facilities.

\section{B. BOT Model}

BOT (Build-Operate-Transfer)model, which refers to the transfer of infrastructure construction and operation rights to project sponsors by the government of the host country or the affiliated agency of the project through a concession agreement, and investment by the project sponsor. The formation of a project company is responsible for the financing, construction, operation and maintenance of the project, and it bears the corresponding risks. By charging the service royalties, the project company makes commercial profits and reclaims investment and transfers the entire project at a lower nominal price or transfer to the government without compensation after the expiry of the concession period. The BOT model is widely used in project financing for its flexibility, such as the China Gezhouba Group Corporation and the Kabeli-A Joint Hydropower Project in Nepal. In addition, the BOT model derived a variety of different forms on the basis of the original, such as BOO(Build-Own-Operate), BOOT(Build-OwnOperate-Transfer), BLT (Build- Lease-Transfer), BTO (BuildTransfer-Operate).

\section{PPP Model}

PPP (Public-Private Partnership) is a public-private partnership or government-enterprise joint venture model. It means that public institutions (government) and private institutions (social private capital) jointly provide public goods or services on the basis of a project, give full play to their respective advantages, share risks and share revenue. The PPP model can help the host government reduce the financial burden, expand the sources of construction funds, reduce operating costs and share risk. Therefore, it is widely used in overseas infrastructure construction. The PPP model can not only meet the Chinese government's public welfare demand for the economic support of the countries along the line, but also realize the profit goal of the enterprise itself. It is an effective way to establish mutually beneficial relationship between the government and the enterprises [2].

As a financing route of overseas infrastructure construction projects, the PPP model and the BOT model have certain commonalities, such as project orientation, risk sharing, and diversification of credit structures, but there are also obvious differences. First of all, government departments have become more involved and have played an important role from beginning to end in the PPP model. In the BOT project, the government generally issued a concession agreement at the initial stage of the project to authorize the private sector to carry out construction and operations. It does not directly or indirectly participate in other project processes and only acts as a project supervisor. Second, the risk sharing of the PPP model is more reasonable. In the BOT model, since the private sector did not participate in the project design and project initiation at the initial stage of the project, the ability to control risk was weak, and all risks of the project were borne by the private sector, which also caused financing difficulties and other issues, limiting the participation of social capital. Enthusiasm. In PPP model, the private sector usually only bears commercial risks, while government departments bear more systematic risks. The government and social capital allocate their power and responsibility according to their own advantages, share risks, and enhance the ability of PPP projects to resist risks. Finally, the PPP model is more applicable to the construction of quasioperating public infrastructure, and for the operational infrastructure construction projects, the BOT model is more applicable [3].

\section{DATA OF FINANCING MODELS UNDER THE "BELT AND ROAD” INITIATIVE}

According to the data collected by Bloomberg, in 2016, the syndicated loans in the Asia Pacific region (excluding Japan) amounted to US\$ 482.3 billion, and a total of 1,428 loans were completed, which represents an increase of $4.7 \%$ from the US\$ 460.5 billion in 2015. Similar to the past few years, the 
Chinese onshore market is a huge driver of loan growth in the Asia Pacific region in 2016, totaling US\$128 billion, accounting for $26.1 \%$ of the entire Asia-Pacific market.

Companies use syndicated loans to meet a variety of financing needs. The largest share of loan use is refinancing, which accounts for about $25 \%$ of the entire loan market. Project financing and acquisition financing ranked second and third respectively, accounting for $23 \%$ and $17 \%$ respectively.

Bank of China relied on 353 loans, 13.15\% of market share ranked first in the Asia-Pacific region (excluding Japan) list of main entrusted managers, and DBS Bank and HSBC ranked in the market share of $3.32 \%$ and $3.21 \%$ respectively. Ranked 2 nd and 3rd in the rankings.

Syndicated loans have always been one of the most important financing methods in the international financial market. 2016 can be described as the year of overseas mergers and acquisitions by Chinese domestic companies. According to relevant statistics, overseas acquisitions by mainland Chinese companies have achieved substantial growth in 2016. The transaction volume has increased by $142 \%$ (close to 2.5 times), and the transaction amount has increased by 246 percent (close to 3.5 times) to 221 billion US dollars, more than the previous four years. The sum of the amount of M\&A transaction. Most of these are financed by syndicated loans. This shows that syndicated loans play a decisive role in cross-border business.

\section{COUNTERMEASURES AND SUGGESTIONS ON INVESTMENT AND FINANCING OF OVERSEAS INFRASTRUCTURE CONSTRUCTION}

Based on the status of the "Belt and Road" initiative, the funding gap for national infrastructure construction along strategic lines is relatively large, and a single investment and financing model cannot meet the needs of project construction. Therefore, on the basis of organic integration of traditional and innovative financing models, new investment should be continuously explored. In addition, through the analysis of many risks in the process of cross-border infrastructure investment, and in combination with Chinese own strengths and weaknesses, we will select more reasonable ways to participate, and do a good job of anticipating risk assessment and avoidance, which will be an overseas foundation for Chinese companies. Facility construction investment makes reasonable suggestions.

\section{A. Deepen the Multiple Investment and Financing Model and Strengthen the Leverage of Development Finance}

Firstly, development finance and policy finance are used as financing leverage to support the incubation and start-up of projects; and with the support of the AIIB and Silk Road Funds, the selection of key projects is optimized. Secondly, to take full advantage of China's dominant position as the leading investment bank of the Asian Investment Bank, to maintain active communication with countries along the "Belt and Road" initiative in the financing of overseas infrastructure construction, and actively guide countries to give priority to Chinese companies and China in bidding for infrastructure construction projects. standard. Third, in order to mobilize the participation of social capital, we must give full play to the support and support role of Asian infrastructure investment banks and implement more stable profitable projects or products. Continue to promote the application of the publicprivate partnership model. Amplify the role of private capital in foreign investment, achieve diversification of funding sources, marketization of financing methods, and optimize the funding structure for project construction [4].

\section{B. Increase Financial Financing and Implement Cross- Border Infrastructure Asset Securitization.}

The use of bond issuance or proceeds or asset securitization for infrastructure financing has been widely applied in developed countries, but this model is extremely rare in developing countries along the "Belt and Road" initiative. The realization of cross-border infrastructure asset securitization refers to the issue of financing through the issuance of bonds and targets the proceeds from the operation of cross-border infrastructure projects. This type of investment and financing model implements asset securitization for overseas infrastructure that has already been built, and provides the possibility of exiting as a channel. Asset securitization is implemented as social private capital, especially for small amounts. Capital participation brings new opportunities. In recent years, the proportion of Chinese domestic infrastructure construction adopting direct financing from financial markets has increased year by year, and the means have become increasingly diversified. Therefore, when invest infrastructure construction in neighboring countries, we can draw on the successful experiences of developed countries and China, and encourage some competent Chinese companies to form joint investment and financing entities with overseas investment institutions, host governments, or foreign companies. The purpose is to issue medium and long-term silk road construction bonds, and to directly finance the domestic and foreign financial markets. In addition, it will be established in most parts of Asia. After perfecting the regional bond market, it is necessary to vigorously promote financial integration in the Asian region, share the national infrastructure construction projects along the " Belt and Road" initiative, and publicly raise funds needed for construction in the financial market to share risks. It is also possible to establish the "Belt and Road" cross-border infrastructure stock exchanges to guide the huge savings surplus funds and private capital in the Asian capital market to the infrastructure sector and create innovative financing platforms.

\section{Accelerate the Internationalization of the $R M B$ and Accelerate the Pace of "Going out" of Commercial Banks}

On the one hand, as the demand for RMB in the world currency system continues to grow, the willingness of Chinese enterprises to "become global" is urgent. It is imperative to promote the internationalization of RMB. First of all, it is necessary to reduce the regulation of foreign direct investment in foreign direct investment and create loose foreign exchange conditions for cross-border investment by enterprises. In addition, in order to alleviate the currency exchange rate risks faced by Chinese companies overseas, they should actively promote regional financial cooperation, and prior agreement on currency exchange rates in the concession agreements of BOT and other models. It is also possible to establish offshore 
accounts, absorbing multilateral development institutions at home and abroad to participate in financing, avoiding currency exchange rates and other economic risks to a certain extent.

On the other hand, as the main force for the internationalization of Chinese-funded commercial financial institutions, the five state-owned banks should expand the scale of their overseas branches. According to the strategic deployment of the Belt and Road Initiative and the global development trend, Pakistan, Malaysia and Indonesia will have more room for future growth. The demand for infrastructure construction in the Middle East and North Africa will grow more steadily in the future. Therefore, with the deepening of the reform of Chinese commercial banks and the acceleration of the pace of internationalization, Chinese-funded banks can choose to deploy overseas in areas with greater demand and development space, and expand the scale of investment gradually .

\section{Strengthen the Role of Government Guidance and Services, Strengthen the Company's Overseas Operations and Risk Management}

Chinese companies face many uncertainties and potential risks overseas, and they lack corresponding crisis management experience. At this time, the government should fully grasp the host country's political, economic and social conditions, strengthen the situation and trends, release the country risk assessment report regularly, and provide policy consulting, risk warning and other services. In addition, the government should strengthen communication with overseas business associations and promotion agencies, understand the host country's business conditions, market rules and customs, etc., and build a platform for overseas investment and financing. On this basis, we will strengthen cooperation with professional consulting agencies, make more professional analysis of investment needs and risks in various countries, guide enterprises and financial institutions to conduct differentiated investment, and ensure the maximum revenue and safety of funds. For the host country's domestic security and security issues, the crisis management agencies should be commissioned to conduct safety education and emergency knowledge training, and establish an efficient security mechanism. In addition, specialized institutions are required to assist our overseas investment companies in localization work, such as the localization of corporate culture, integration of employees, participation in cultural undertakings, and fulfillment of social responsibilities, etc [5].

\section{CONCLUSION}

The implementation of the " Belt and Road" initiative is based on infrastructure construction as a breakthrough to achieve interconnection. Years of experience in infrastructure construction have resulted in a more complete export model in China, and overseas infrastructure construction has been carried out through development financial institutions, BOT model and PPP model or other innovative investment models. Although opportunities and risks coexist, we strive to discover and avoid risks in Chinese enterprises in a timely manner, deepen the multiple investment and financing model, take into account the economic benefits and social responsibilities of the countries in the surrounding regions, achieving business cooperation and mutual development [6]. All of these will surely inject new driving force into the economic growth of world.

\section{ACKNOWLEDGMENT}

I would like to express my gratitude to all who helped me during the writing of this thesis. Any progress that I have made is the result of their profound concern and selfless devotion. Particularly, I am greatly obliged to my sincere tutor, Truly, without her painstaking efforts in revising and polishing my drafts, the completion of this thesis would not have been possible. Besides her help with my thesis, she has also given me much advice on the methods of doing research, which is of great value to my future academic life.

Last but not least, I appreciate all the friends and family members who have offered me help. Without their help, I could not have finished my study and this thesis.

\section{REFERENCES}

[1] SUN De-mei. Stability Analysis of PPP Mode in Infrastructure Construction Based on Evolutionary Game Theory[A]. University of Ghana (UG) 、 Ghana Institute of Management and Public Administration(GIMPA)、University of Cape Coast (UCC)、American Society for Public Administration (ASPA)、University of Electronic Science and Technology of China (UESTC).Proceedings of 2017 International Conference on Public Administration(12th) \& International Symposium on West African Studies (1st)(Volume I )[C].University of Ghana (UG) 、 Ghana Institute of Management and Public Administration(GIMPA)、University of Cape Coast (UCC)、American Society for Public Administration (ASPA)、University of Electronic Science and Technology of China (UESTC),2017:9.

[2] Wenqian Huang. Comparative Analysis on BOT, PPP and ABS Project Financing Models[P]. 6th International Conference on Electronic, Mechanical, Information and Management Society,2016.

[3] Junjie Zhang,Lund Shaun. The Development of Sustainable Highway Infrastructure in the Strategy of One Belt and One road[P]. 2016 1st International Symposium on Business Cooperation and Development,2016

[4] Xinran Ge,Ersi Liu,Ke Yan. The Heat Analysis of Chinese Enterprises in Laos Transportation Infrastructure Investment under the Belt and Road Initiative[P]. 2016 1st International Symposium on Business Cooperation and Development,2016

[5] Zhongqi Deng,Shunfeng Song,Yongjun Chen. Private participation in infrastructure project and its impact on the project cost $[\mathrm{J}]$. China Economic Review,2016,39.

[6] SYZDYKOVA AiGERiM. "Kazakhstan 2050" \& "One Belt,One Road"the Effects on Kazakhstan's Transport Infrastructure Development[D],2017 